\title{
EXAME PAPANICOLAOU: UM ESTUDO ETNOGEOGRÁFICO DAS REPRESENTAÇÕES DE UM GRUPO DE MULHERES EM XONIM DE BAIXO, GV - MG
}

\author{
Vanessa Loyola Lopes ${ }^{1}$ \\ Maria Aparecida Sá Xavier ${ }^{2}$
}

\begin{abstract}
RESUMO: As representações simbólicas são forma de conhecimento socialmente elaborado, neste sentido, esta pesquisa procurou analisar as representações de um grupo de mulheres de Xonim de Baixo, em relação à prevenção, tratamento e cura do câncer de colo de útero. Sabe-se que este câncer tem altas taxas de morbimortalidade, e o desafio é a não adesão das mulheres ao exame Papanicolaou. A pesquisa propôs compreender como, por quais motivos, e quais as representações desse exame para um grupo de mulheres. As representações do corpo feminino e do processo saúde/doença foram questões secundárias analisadas. O método etnogeográfico foi utilizado, a fim de privilegiar a socioespacialidade contextualizada na historicidade e subjetividade do grupo. Nas representações simbólicas de saúde/doença/cura, foi identificada grande distância entre as categorias do saber biomédico e as categorias dos saber local. Observou-se forte resistência ao saber biomédico, no momento em que esta mulher percebe-se invadida em seu território primeiro, seu corpo. Diante de tal situação, estas mulheres escolhem a forma de buscar por saúde pautada na questão da fé e da tradição, e portando legitimado através do uso de plantas com fins medicinais e universo mágicoreligioso. Como desmembramento do estudo, foram analisados os fatores que dificultam o acesso ao preventivo, como o acesso ao médico, vergonha de expor o corpo, e relação de cotidianidade face a face exposto na fofoca como controlador social. Apenas quando os programas de políticas públicas observarem os saberes locais e sua socioespacialidade, expressa na territorialidade, poder-se-á pensar num serviço de saúde com efetividade.
\end{abstract}

PALAVRAS-CHAVE: Representação; Exame Papanicolaou; Corpo feminino; Etnogeografia; Socioespacialidade.

\begin{abstract}
The symbolic representations are socially elaborated form of knowledge in this sense, this research sought to examine the representations of a group of women Xonim Low in relation to prevention, treatment and cure of cancer of the cervix. It is known that this cancer has high rates of morbidity and mortality, and the challenge is noncompliance of women to the Pap smear. The proposed research to understand how, for what reasons and what are the representations of this exam for a group of women. The representations of the female body and the health / disease issues were considered secondary. Ethnogeography The method was used in order to focus on socio-contextualized in the historicity and subjectivity of the group. In symbolic representations of health / disease / cure was identified large distance between the categories of biomedical knowledge and the categories of local knowledge. There was strong resistance to biomedical knowledge, the moment you realize this woman invaded their territory in the first, his body. Faced with this situation, these women choose how to check for health ruled on the issue of faith and tradition, and carrying through the legitimate use of plants for medicinal and religious-magical universe. How to break up the study analyzes the factors that hinder access to prevention, such as access to medical shame of exposing the body, and relationship of daily life in the face exposed in the gossip as social control. Only when the public policy programs to observe their local knowledge and socio-expressed in territoriality, it may be thought in a health effectively.
\end{abstract}

KEYWORDS: Representation; Pap smear; Female body; ethnogeography; Socio.

\footnotetext{
${ }^{1}$ Professora, Fisioterapeuta, mestre em estudos territoriais, UNIVALE, GV, MG. van_loyola@hotmail.com

${ }^{2}$ Professora/pesquisadora, Farmacêutica, doutorado em Geografia-PGGeografia, UFF, Niterói, RJ., Colaboradora do PG Gestão Integrada do Território, UNIVALE, GV, MG. airamxavier@yahoo.com.br 


\section{INTRODUÇÃO}

As representações sociais são uma forma de conhecimento socialmente elaborado e compartilhado, com um objetivo prático, e contribui para a construção de uma realidade comum a um conjunto social (JODELET, 2002). Partindo destes pressupostos, foram analisadas as representações de um grupo de mulheres em Xonim de Baixo (XB), distrito de Governador Valadares (GV), buscando enfatizar a forma como estas buscavam por prevenção e cura sobre o câncer de colo de útero.

Em acordo com o saber biomédico, sabe-se que o câncer de colo de útero é responsável por altas taxas de morbimortalidade entre as mulheres, representando ainda um grande problema de saúde pública. Segundo ainda a biomedicina, essas altas taxas põem em destaque uma questão grave em relação à saúde da mulher, sendo a prevenção apontada como um caminho importante. Entretanto, apesar dos esforços crescentes no sentido de maximizar a eficiência dos programas de prevenção ao câncer cervical, a permanência de taxas de incidência e mortalidade altas por esta doença revela que tais medidas não se mostraram suficientes para a efetividade dos programas.

Um dos grandes desafios para a biomedicina e seus profissionais é a não adesão da mulher ao chamado "exame Papanicolaou". Segundo o Ministério da Saúde (2000), Zeferino et al. (2001), INCA
(2004), a mulher frequentemente não realiza o exame Papanicolaou por vergonha, medo de expor seu corpo, desmotivação, dificuldade de acesso ao exame, entre outros fatores, sendo essa nossa primeira hipótese. Nesse sentido, esta pesquisa propôs, num primeiro momento compreender como, e por quais motivos algumas mulheres resistem ao "exame Papanicolaou". Para tanto intentamos compreender as representações do exame Papanicolaou para estas mulheres. As representações do corpo feminino e do processo saúde/doença foram questões secundárias, que corroboraram para o debate do problema inicial. Privilegiou-se a socioespacialidade contextualizada na historicidade e subjetividade desta mulher (sua experiência espacial, incluindo o corpo), sua maneira de se inserir no mundo, o ethos e seu processo de saúde/doença/cura. Ambiciona-se corroborar para um debate crítico sobre a saúde da mulher, através de estudos interdisciplinares que permitam uma aproximação entre os saberes êmicos e éticos.

A mulher está para além de apenas um corpo físico, e ocupa um lugar histórico-social no espaço, ou, como sugere Tuan (1983), sendo seu próprio corpo como espaço (território primeiro), mostrando uma identidade construída em suas relações, apresentando, assim, uma diversidade em todas as dimensões. Portanto, para alcançar a meta de realizar o exame Papanicolaou em todas as mulheres, será necessário compreender a mulher para além do 
biologismo, do binarismo feminino/masculino

do patriarcado, evidenciando sua espacialidade e territorialidade. É necessária a compreensão da multiplicidade da mulher em todos seus papéis sociais, ampliando o conhecimento na área da saúde fortalecendo o diálogo com outras áreas, como a sociologia, psicologia, antropologia e geografia da saúde.

\section{OBJETIVO}

Este estudo tem como objetivo trabalhar as representações de um grupo de mulheres que não realizam o exame Papanicolaou no distrito de Xonim de Baixo (XB), Governador Valadares-MG, com a finalidade de compreender suas formas de prevenção e tratamento do câncer de colo de útero.

\section{METODOLOGIA}

Foi realizada uma pesquisa qualitativa, através de um estudo etnogeográfico de um grupo de vinte e cinco mulheres que não realizam o exame Papanicolaou no distrito de Xonim de Baixo, Governador Valadares-MG. $\mathrm{O}$ método foi adaptado da antropologia, para a geografia, a fim de ser operacionalizado dentro da problemática proposta nesta pesquisa. Continuar-se-á observando o modo de vida das interlocutoras, entretanto, a análise principal é o espaço-espacialidade, território, territorialidades (nos processos, ações). Entendendo o espacializar dos sujeitos

sociais principalmente no processo saúde/doença/cura.

Nesta etnogeografia foi utilizado diário de campo, observação participante, entrevistas em profundidade com roteiro memorizado, além de fotografias e mapa interpretativo.

A técnica da observação participante tem como pré-requisito a presença constante do observador no campo, convivendo com os informantes no seu ambiente natural durante algum tempo. A interação social produzida ocasiona modificações no contexto observado, ao mesmo tempo em que torna o observador parte das influências do contexto. Em Xonim de Baixo, houve a observação dos hábitos de vida das mulheres entrevistadas, mas também das demais pessoas do distrito; observação mais direta (participante) na Estratégia de Saúde da Família (ESF) e em atividades do posto (palestra no Dia da Mulher, por exemplo); observação participante do distrito de XB num sentido mais amplo e mais abrangente, mas atento ao detalhe, ao singular, aos imponderáveis da vida real.

A transcrição das entrevistas obedeceu às orientações de Minayo e Sanches (1993), sendo que a fala torna-se reveladora de condições estruturais, de sistema de valores, normas e símbolos e reproduz as representações de grupos determinados em condições históricas, socioeconômicas e culturais específicas. Por fim, os dados foram 
analisados segundo abordagem qualitativa numa perspectiva etnográfica, através da busca de uma aproximação da descrição densa de Geertz (2008).

\section{RESULTADOS E DISCUSSÕES}

Como resultado, e para uma melhor compreensão dos espaços vividos e da localização das mulheres entrevistadas na pesquisa de campo, apresentamos um mapa mental interpretativo do distrito de Xonim de Baixo. Neste mapa estão localizados alguns topos importantes no cenário do distrito (como ESF, delegacia, BR, igreja, escola, avenidas, entre outros) e as casas das mulheres entrevistadas. Observa-se que os nomes das interlocutoras foram substituídos por nomes de flores para preservar suas identidades. Através do mapa interpretativo, podemos apresentar as espacialidades destas mulheres, analisando seus itinerários e caminhos percorridos, quando as mesmas saem de casa à tarde, levam as crianças na escola, param nas barracas de coco para saberem das últimas notícias; quando saem de casa á noite para irem ao bar do Gaúcho, ou a alguma igreja evangélica ou católica.

Figura 1- Mapa interpretativo do distrito de Xonim de Baixo, GV, MG.

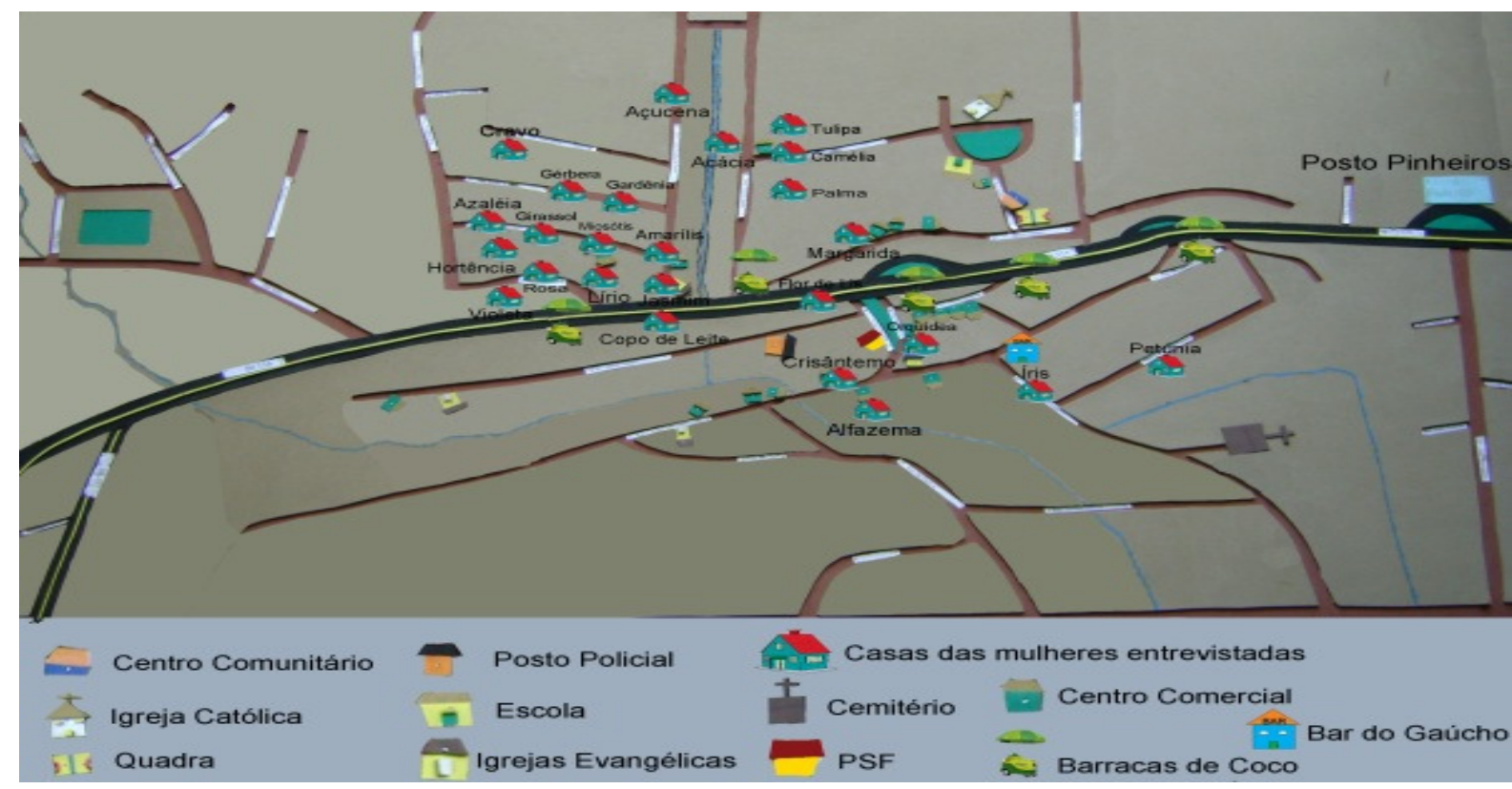

Fonte: LOPES, 2011.

A análise geoistóricas do grupo pesquisado trouxe embasamento para o conhecimento das características peculiares no processo saúde/doença/cura.
Observou uma classificação simbólica das doenças usando como base a explicação que cada grupo cultural dá para a origem das patologias. Há tratamento baseado no saber biomédico tradicional (médicos, 
medicamentos alopáticos); no universo mágico-religioso (benzedor, rituais de fé católicos e evangélicos); no uso das plantas como fins medicinais e um hibridismo associando estes saberes.

Abaixo se apresenta um quadro com a classificação de doenças e seu respectivo tratamento.

Quadro 1: classificação das doenças e seus respectivos tratamentos.

\begin{tabular}{|l|l|}
\hline $\begin{array}{l}\text { Doenças que médico } \\
\text { não cura }\end{array}$ & $\begin{array}{l}\text { Tratada pelo universo } \\
\text { mágico-religioso }\end{array}$ \\
\hline $\begin{array}{l}\text { Doenças que "não } \\
\text { tratamos" }\end{array}$ & $\begin{array}{l}\text { Tratada pelo saber } \\
\text { biomédico }\end{array}$ \\
\hline Doenças híbridas & $\begin{array}{l}\text { Articulação dos dois } \\
\text { saberes - biomédico e } \\
\text { universo mágico } \\
\text { religioso }\end{array}$ \\
\hline $\begin{array}{l}\text { Doenças tratadas } \\
\text { com uso das plantas }\end{array}$ & $\begin{array}{l}\text { Articulação dos dois } \\
\text { saberes - biomédico e } \\
\text { plantas; uso exclusivo } \\
\text { das plantas }\end{array}$ \\
\hline
\end{tabular}

Fonte: LOPES, 2011.

Pode-se observar ainda uma classificação local das plantas utilizadas como fins medicinais e seus respectivos tratamentos. Veja quadro abaixo:

Quadro 2: $\quad$ Plantas com fins medicinais e suas finalidades terapêuticas.

\begin{tabular}{|l|l|}
\hline \multicolumn{1}{|c|}{ Chá } & \multicolumn{1}{c|}{ Doença } \\
\hline São Caetano & $\begin{array}{l}\text { Dor no joelho. } \\
\text { Forma de usar: Banhar } \\
\text { o local e tomar o chá } \\
\text { (uma colher). }\end{array}$ \\
\hline Capim guiné & Reumatismo \\
\hline Hortelã pimenta & Gripe \\
\hline Folha de laranja & Tosse \\
\hline Erva cidreira & $\begin{array}{l}\text { Gripe; baixar pressão } \\
\text { alta }\end{array}$ \\
\hline
\end{tabular}

\begin{tabular}{|c|c|}
\hline Alecrim & $\begin{array}{l}\text { Baixar pressão alta } \\
\text { Forma de usar: tomar } \\
\text { gelado }\end{array}$ \\
\hline Amora & Baixar pressão alta \\
\hline Folha de chuchu & Baixar pressão alta \\
\hline Carqueja & Baixar pressão alta \\
\hline Camomila & $\begin{array}{l}\text { Problema nos nervos e } \\
\text { febre }\end{array}$ \\
\hline $\begin{array}{l}\text { Folha de } \\
\text { carambola }\end{array}$ & Problema nos nervos \\
\hline Chá de mate & Problema nos nervos \\
\hline Boldo & Estômago; azia \\
\hline Santa Maria & $\begin{array}{l}\text { Verme, ameba, } \\
\text { "xistose" - } \\
\text { (esquistossomose). }\end{array}$ \\
\hline Raiz da salsa & Inflamação e corrimento \\
\hline Transagem & $\begin{array}{l}\text { Inflamação, infecção, } \\
\text { protege contra tudo, } \\
\text { útero }\end{array}$ \\
\hline Arnica & $\begin{array}{l}\text { Inflamação, infecção, } \\
\text { dor, útero }\end{array}$ \\
\hline Folha de algodão & 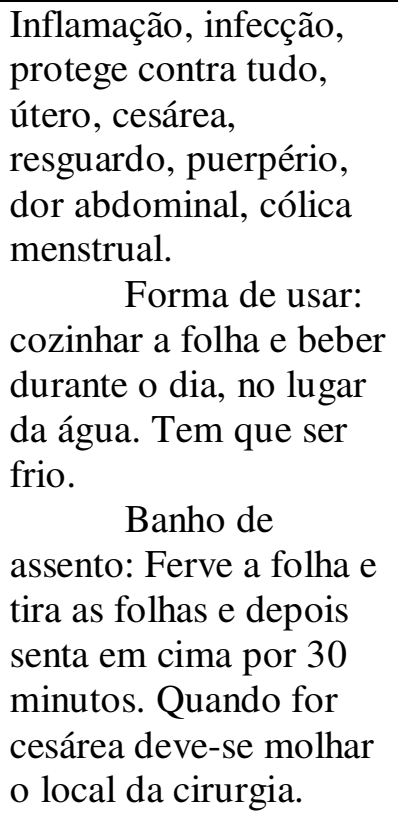 \\
\hline $\begin{array}{l}\text { Folha de } \\
\text { meracilina }\end{array}$ & Útero \\
\hline $\begin{array}{l}\text { Flor de rosa } \\
\text { branca }\end{array}$ & Infecção \\
\hline Chá de noni & Inflamação, anemia \\
\hline Cana de macaco & $\begin{array}{l}\text { Infecção urinária } \\
\text { masculina e feminina, } \\
\text { problema no útero }\end{array}$ \\
\hline Poejo & $\begin{array}{l}\text { Cicatrizante e } \\
\text { antisséptico }\end{array}$ \\
\hline
\end{tabular}

Fonte: LOPES, 2011. 
Estes saberes êmicos, parafraseando Geertz e corroborando com as pesquisas de Xavier (2004, 2009), em XB representam uma parcela grande da sociedade estudada, pois muitos dos sujeitos sociais escolhem prevenir e tratar das doenças através destes saberes perpassados entre as gerações a se submeterem a saberes científicos da biomedicina.

Elas observam os atos de suas antecessoras (mães e avós, especialmente) no processo saúde/doença/cura e repetem os exemplos, pois confiam nestas pessoas e sabem que suas histórias de vida foram bem sucedidas. Além disso, como afirma Boltanski (1989) é uma oportunidade de reativar as lembranças de família, de falar da mãe ou da avó, enfim de assinalar as oposições e semelhanças entre o passado e o presente.

A escolha das mulheres desta pesquisa em buscar por saúde se baseando em outros saberes de cura está embasada na tradição e cultura em que este ser social está inserido, através de sua territorialidade, do meio que conhece, que está familiarizado, portanto processos socioculturais, que dependem de um espaço/tempo, uma geoistória. Necessário se faz compreendê-lo em sua atividade instrumental e simbólica.

O uso que faz a população das plantas com fins medicinais não está calcado nos mesmos pressupostos que sustentam os usos biomédicos, ou seja, baseado em conhecimentos construídos com base na experimentação científica. Os outros saberes de cura ancora-se em princípios que levam em consideração a possibilidade de intervenção divina e/ou espiritual no processo de adoecimento, tratamento e cura, assim como na capacidade concedida a algumas pessoas para diagnosticar e curar os males do corpo e da alma (ARAÚJO, 2002; XAVIER, 2004, 2009). As informantes reportam à importância da fé para que se tenham benefícios com o uso do chá. A análise dos dados demonstrou que para as informantes, a doença atua no corpo para além da lógica atribuída ao saber biomédico. Os aspectos mágico-religiosos presentes nos rituais católicos, evangélicos, de curandeiros ou benzedores, foram tidos como responsáveis pela cura de doenças espirituais, que refletem no corpo físico, sendo que o uso dos chás segue esta lógica.

Em Xonim de Baixo, durante a pesquisa de campo, tentou-se responder aos questionamentos iniciais sobre as representações simbólicas das mulheres entrevistadas sobre o exame Papanicolaou, em relação ao corpo feminino e ao processo saúde/doença/cura. Foi importante conhecer as diversas formas que as mulheres se vêem, como percebem seus corpos e as ações na territorialidade, pois é este conhecimento empírico que lhes dá embasamento para realizar as escolhas em seu processo saúde/doença em suas trilhas de vida.

\section{Exame Papanicolaou}

As mulheres apresentam dificuldade em identificarem o exame pelo nome 
Papanicolaou, mas quando referida a sua forma popularmente conhecida - preventivo -, a maioria das mulheres relata conhecer o exame; sabem a forma como é realizado, sua importância.

Entretanto, apesar dessas mulheres terem informação sobre o exame, esta, em geral, não é a forma que elas escolhem para prevenção do câncer de colo de útero. Por conhecerem seus próprios corpos, elas preferem buscar por esta prevenção através de outras formas de curar (chás, por exemplo), onde não há constrangimento, medo, dor ou vergonha. Pelo contrário, há confirmação e certeza do prognóstico através das "histórias de vidas" de seus antepassados.

\section{Saúde/ doença}

A subjetividade da doença, para estas mulheres está pautada nos sintomas, sinais ou representações e quando não há sinais que demonstrem alguma alteração em seu funcionamento normal do corpo, não há por que buscar por tratamento, pois não há doença. Há uma percepção própria do processo saúde/doença/cura, onde se observa que algumas doenças não são reconhecidas como tal e as pessoas enfatizam apenas o adoecimento. Outras pessoas reconhecem a doença, mas escolhem outro tipo de tratamento ou nenhum tratamento. Em geral, elas reconhecem o próprio corpo e percebem quando inicia o processo do adoecimento, qual o melhor período para buscar tratamento e elegem o tratamento que melhor corresponde ao seu modo de vida, à sua interpretação do processo saúde/ doença e cura.

\section{Corpo Feminino}

No universo das pesquisadas, mesmo morando em uma zona rural de um distrito de Governador Valadares, estão sendo influenciadas de alguma forma pela pósmodernidade, que adentra seu distrito, sua casa, seu corpo, sua vida. Como consequência, teremos mulheres mais ou menos revolucionadas por esse movimento, mulheres que terão pleno domínio de suas vidas, seus corpos e escolherão como viver em sociedade, em suas casas, com seus corpos. Pode-se observar esse processo de transformação na vida de tais mulheres quando elas escolhem sua opção sexual, quando escolhem a maneira de cuidar de seu corpo, inclusive no processo saúde/doença, quando decidem a forma de expressar e viver sua territorialidade.

Analisaremos a seguir os fatores que dificultaram o acesso ao exame Papanicolaou.

\section{Fatores que dificultam o acesso ao exame Papanicolaou}

Foi relatado que uma das maiores dificuldades para a realização do exame em XB é a dificuldade de acesso, pois são apenas 10 fichas para consultar com médico (na terça e quinta-feira) e 10 fichas para realizar o exame Papanicolaou com a enfermeira (duas vezes por mês). Uma dificuldade apresentada foi a incerteza de atendimentos médicos. 
Outro fator citado, e que prejudica a busca pelo exame Papanicolaou, como forma de prevenção do câncer de colo de útero, é a vergonha. Vergonha de si mesmo, do seu corpo, do outro, do olhar do outro.

$\mathrm{Na}$ localidade, muitas mulheres não realizavam os exames por: vergonha de exposição do corpo pelo constrangimento de expor sua nudez e por padrões sociais de beleza impostos por interesses econômicos; vergonha pela diferença de gênero (paciente e médico); medo da fofoca, de ter sua vida e seu corpo exposto na sociedade, gerando uma vergonha social.

Uma situação em particular chamou a atenção, visto que muitas pessoas preferiam realizar o exame em GV ao invés de realizar o exame em $\mathrm{XB}$, pois existia uma vergonha do cotidiano, no constrangimento social onde há laços afetivos, profissionais, de amizades, parentescos, ou apenas de conhecidos do distrito. Mesmo sendo mais difícil realizar o exame em GV, devido ao gasto financeiro e de tempo, muitas mulheres escolhiam GV a $\mathrm{XB}$.

\section{CONSIDERAÇÕES FINAIS}

A interpretação de mundo, neste trabalho de pesquisa, pode ser percebida através da territorialidade/espacialidade deste sujeito social (mulher), observada a partir da descrição das práticas cotidianas, em seus movimentos rotineiros; nas trajetórias de vida através da descrição de suas casas e seu distrito, além da relação entre Governador Valadares e Xonim de Baixo. A análise interpretativa do vivido mostrou-se reveladora ao demonstrar as resistências realizadas através do corpo e seu ethos, no seu processo saúde/doença/cura. Esta mulher usa seu corpo como seu espaço primeiro, seu território. No momento em que o poder biomédico enfatiza para a mulher como ela deve agir e se portar em seu território vivido, (principalmente quando decide qual terapêutica ela deve seguir), há uma resistência da mulher, que percebe que sua privacidade, seu poder de escolha, autonomia, está sendo ameaçada (XAVIER, 2011, comunicação pessoal, mimeo). Seria o público determinando conceitos e formas de vida para as pessoas, no campo do privado. Nesse caminho do pensamento, o corpo seria conceito primeiro de privacidade, de sensação de pertencimento desses sujeitos sociais, justificando, portanto, a resistência destas mulheres ao exame Papanicolaou e às terapêuticas propostas pelo poder biomédico. Mais além da questão da privacidade do corpo, há ainda questões ligadas à fé e tradição cultural que impulsionam estas mulheres a escolherem outros saberes de cura em seu processo saúde/doença/cura e a verem seu corpo de forma diferente da biomedicina.

\section{REFERÊNCIAS}

ARAÚJO, Melvina A. M. Das ervas medicinais à fitoterapia. São Paulo: Ateliê Editorial/ Fapesp, 2002. 
BOLTANSKI, LUC. As classes sociais e o corpo. Rio de Janeiro: Edições Graal, 1989.

BRASIL. Ministério da Saúde. XI Conferência Nacional de Saúde. Relatório final. Brasília: Ministério da Saúde; 2000.

GEERTZ, Clifford. A interpretação das culturas. Rio de Janeiro: LTC, 2008.

INSTITUTO NACIONAL DE CÂNCER; MINISTÉRIO DA SAÚDE; Secretaria de Estado da Saúde. Coleta do Papanicolaou e ensino do autoexame da mama: manual de procedimentos técnicos e administrativos. $2 \mathrm{a}$ ed. São Paulo: INCA, 2004.

JODELET, D. Representações sociais: um domínio em expansão. In: JODELET, D. As Representações sociais. Rio de Janeiro: Eduerj, 2002.

LOPES, V.L. Exame Papanicolaou: um estudo etnogeográfico das representações de um grupo de mulheres em Xonim de Baixo, GV- MG. Dissertação Mestrado, Programa de Pós-graduação Stricto Sensu em Gestão Integrada do Território, UNIVALE, 2011.

MINAYO, M. C.; SANCHES, O.

Quantitativo-qualitativo: oposição ou complementaridade? Caderno de Saúde Pública, Brasil, v. 9, n.3, 1993.

TUAN, Yi-Fu. Espaço e lugar: A perspectiva da experiência. São Paulo: Difel, 1983.

XAVIER, Maria Aparecida de Sá. Estudo das Representações Simbólicas de Saúde/Doença/Cura na comunidade do Saco do Mamanguá, Paraty, RJ.

Dissertação Mestrado, PGCA, UFF, 2004.181p.
. O Ticumbi e a arte de curar na comunidade da Vila de Itaúnas, Conceição da Barra, ES, como expressões de espacialidades. Tese de doutorado, Niterói, RJ: PP Geografia, UFF, 2009.

ZEFERINO, L.C. et al., Conhecimento, atitude e prática do exame de Papanicolaou em mulheres com câncer de colo uterino.

Caderno Saúde Pública, Rio de Janeiro, julago, 2001. 